\title{
Stimulation of Lung Epithelial Liquid Clearance by Endogenous Release of Catecholamines in Septic Shock in Anesthetized Rats
}

\author{
J. F. Pittet, J. P. Wiener-Kronish, M. C. McElroy, H. G. Folkesson, and M. A. Matthay \\ Cardiovascular Research Institute and Departments of Anesthesia and Medicine, University of California, San Francisco, \\ California 94143
}

\begin{abstract}
Exogenous administration of $\beta$-adrenergic agonists has previously been reported to increase lung liquid clearance by stimulation of active sodium transport across the alveolar epithelium. We hypothetized for this study that endogenous release of epinephrine in septic shock would stimulate liquid clearance from the airspaces in rats. Liquid clearance from the air spaces was measured by the concentration of protein over $4 \mathrm{~h}$ in a test solution of $5 \%$ albumin instilled into one lung. Bacteremic rats developed severe systemic hypotension and metabolic acidosis that was associated with a 100 fold rise in plasma epinephrine levels. There was a $100 \%$ increase in liquid clearance from the airspaces of the lung in the bacteremic compared with control rats. To determine the mechanisms responsible for this accelerated lung liquid clearance, amiloride $\left(10^{-3} \mathrm{M}\right)$, a sodium transport inhibitor, was added to the air spaces. Amiloride prevented the increase in liquid clearance from the airspaces, indicating that this effect depended on increased uptake of sodium across the lung epithelium. The addition of propranolol $\left(10^{-4}\right.$ or $\left.10^{-5} \mathrm{M}\right)$ to the instillate also prevented the acceleration in alveolar liquid clearance in the bacteremic rats. We conclude that the release of endogenous catecholamines associated with septic shock markedly stimulates fluid clearance from the distal airspaces of the lung by a $\beta$-adrenergic mediated stimulation of active sodium transport across the epithelial barrier. This data provides evidence for a previously unrecognized mechanism that can protect against or hasten the resolution of alveolar edema in pathological conditions, such as septic shock, that are associated with the endogenous release of catecholamines. (J. Clin. Invest. 1994. 94:663671.) Key words: alveolar epithelium • lung liquid clearance - catecholamines $\cdot P$. aeruginos $a \cdot$ pulmonary edema $\bullet$ sepsis, bacterial
\end{abstract}

\section{Introduction}

The exogenous administration of $\beta$-adrenergic agonists has been reported to stimulate epithelial sodium transport in vitro in iso-

Address correspondence to Michael A. Matthay, M.D., Box 0130, Cardiovascular Research Institute, University of California, San Francisco, CA 94143.

Received for publication 13 October 1993 and in revised form 17 March 1994.

J. Clin. Invest.

(C) The American Society for Clinical Investigation, Inc.

0021-9738/94/08/0663/09 \$2.00

Volume 94, August 1994, 663-671 lated alveolar type II cells $(1,2)$, in isolated perfused lungs (3, 4 ), and in vivo in several species (5-7) including recent data from studies of the human lung (8). In isolated alveolar type II cells, $\beta$-adrenergic agonists have been shown to accelerate sodium transport, probably by increasing intracellular cAMP concentration $(1,9,10)$. We have reported that administration of either terbutaline or epinephrine increased liquid clearance from the distal airspaces in normal sheep, an effect mediated through $\beta$ receptors and dependent on an increased uptake of sodium across the lung epithelial barrier (5). $\beta$-adrenergic agonists also increased liquid clearance from the distal airspaces in dogs (6) and rats $(3,7)$.

The endogenous release of epinephrine at the time of labor has been associated with the onset of fluid reabsorption in the fetal lung $(11,12)$, although recent studies indicated that epinephrine might not be the major stimulus for lung liquid reabsorption during labor (13). Increased plasma levels of catecholamines occur in sepsis, the most common clinical disorder leading to the development of acute lung injury and pulmonary edema (14). Therefore, we hypothesized that the endogenous release of catecholamines in sepsis may stimulate sodium transport and liquid clearance from the distal airspaces of the lung.

The first objective of the present study was to investigate whether the administration of gram-negative bacteria $(P$. aeruginosa) would stimulate lung epithelial liquid clearance and/or increase epithelial permeability to protein over $4 \mathrm{~h}$ in anesthetized rats. The results indicated that gram-negative bacteremia was associated with systemic shock and metabolic acidosis, but did not cause an increase in pulmonary epithelial permeability to protein. In fact, there was a marked increase in fluid clearance from the airspaces that was associated with a more than 100fold rise in plasma levels of epinephrine. Therefore, the second and third objectives of these studies were to explore the mechanisms of this accelerated liquid clearance by administering a sodium transport inhibitor, amiloride, or a $\beta$-adrenergic antagonist, propranolol, into the distal airspaces of bacteremic rats. The fourth objective was to determine if this effect could be reproduced by administering a continuous infusion of epinephrine in normal rats. Finally, the fifth objective was to examine the effect of gram-negative septic shock on liquid clearance from the distal airspaces in rabbits, a species which is unresponsive to the stimulating effect of exogenous $\beta$-adrenergic agonists on liquid transport across the pulmonary epithelium $(15,16)$.

\section{Methods}

\section{Rat studies}

SURGICAL PREPARATION AND VENTILATION

Sprague Dawley male rats $(n=39)$ (range $300-350 \mathrm{~g})$ were anesthetized with pentobarbital $(60 \mathrm{mg} / \mathrm{kg}$ intraperitoneal) and anesthesia was 
maintained with half of this dose of pentobarbital every $2 \mathrm{~h}$. A right carotid arterial line was inserted to monitor continuously systemic blood pressure and for blood sampling. Pancuronium bromide $(0.3 \mathrm{mg} / \mathrm{kg} / \mathrm{h})$ was given intravenously for neuromuscular blockade. An endotracheal tube was inserted through a tracheostomy. The animals were supine and ventilated with a constant-volume pump (Harvard Apparatus, Inc., Millis, MA) with an inspired $\mathrm{O}_{2}$ fraction of 1.0 , peak airway pressures of 8-12 $\mathrm{cm} \mathrm{H}_{2} \mathrm{O}$ and positive end-expiratory pressure of $3 \mathrm{~cm} \mathrm{H}_{2} \mathrm{O}$. The respiratory rate was adjusted to maintain the $\mathrm{P}_{\mathrm{a}} \mathrm{CO}_{2}$ between $35-45$ mmHg. All studies were approved by the UCSF animal care committee.

\section{PREPARATION OF INSTILLATE}

A 5\% rat albumin solution was prepared using Ringer's lactate and adjusted with $\mathrm{NaCl}$ to be isoosmolar with the animal's circulating plasma as we have previously published $(5,6,16)$. The solution was filtered through a $0.2-\mu \mathrm{m}$ filter (Nalge Company, Rochester, NY) and $0.5 \mathrm{mg}$ of anhydrous Evan's blue (to confirm location of the instillate at the end of the study) and $3 \mu \mathrm{Ci}$ of ${ }^{125}$ I-labeled human serum albumin (Merck-Frosst, Quebec, Canada) were added to the rat albumin solution. A sample of the instillate was saved for total protein measurement, radioactivity counts and water/dry weight ratio measurements so that the dry weight of the protein solution could be substracted from the final lung water calculation. In some studies (see below), amiloride or propranolol was added to the instillate.

\section{GENERAL PROTOCOL}

For all rat studies, the following general protocol was used. After surgery, a 1-h baseline of stable heart rate and blood pressure was required before alveolar liquid instillation. As a vascular tracer, $3 \mu \mathrm{Ci}$ of ${ }^{131} \mathrm{I}$ labeled human albumin were injected intravenously. This vascular tracer was used to calculate the flux of plasma protein into the air spaces (see below). Then, in septic shock studies, one $\mathrm{ml}$ of $10^{8} \mathrm{cfu}$ of $P$. aeruginosa (PAO1, Fisher immunotype 7) was administered intravenously over 5 min. In control studies, $1 \mathrm{ml}$ of isotonic saline was given over $5 \mathrm{~min}$. Then, the animal was placed in right lateral decubitus position to facilitate liquid deposition into the right lung. The instillate $(3 \mathrm{ml} / \mathrm{kg}$ of the $5 \%$ rat albumin solution with ${ }^{125} \mathrm{I}$-albumin) was delivered into the right lung over $20 \mathrm{~min}$, using a $1-\mathrm{ml}$ syringe and a polypropylene tube $(0.5$ $\mathrm{mm}$ ID). Blood samples were then obtained for ${ }^{131} \mathrm{I}$-albumin and ${ }^{125} \mathrm{I}$ albumin activity and blood gas every hour after the instillation.

The rats were studied for $4 \mathrm{~h}$. Then, the abdomen was opened and the animal was exsanguinated. Urine was sampled for radioactivity counts. Right pleural fluid, and the liver were sampled for bacterial cultures. The lungs were removed through a sternotomy and liquid from the distal airspaces $(0.1-0.2 \mathrm{ml})$ was obtained by passing a propylene tube $(0.5 \mathrm{~mm}$ ID) into a wedged position in the right lower lobe. After centrifugation, the total protein concentration and the radioactivity of the liquid sample was measured. In a prior study, we reported that the concentration of the protein tracers in the liquid sampled by a small catheter wedged into the distal airways was the same as an alveolar micropuncture sample (6). Right and left lungs were homogenized separately for total protein water-to-dry weight ratio measurement, radioactivity counts, and bacteriological cultures.

\section{SPECIFIC PROTOCOLS}

Group 1. Control studies $(n=7)$. After the baseline period, $3 \mathrm{ml} / \mathrm{kg}$ of a 5\% rat albumin solution was instilled into the right lower lobe. Then, the rats were studied for $4 \mathrm{~h}$. After this time interval, the rats were exsanguinated and processed as described above.

Group 2. Intravenous $P$. aeruginosa studies $(n=9)$. After the baseline period, $10^{8} \mathrm{cfu}$ of $P$. aeruginosa (PAO1, Fisher immunotype 7) were administered intravenously over $5 \mathrm{~min}$ before $3 \mathrm{ml} / \mathrm{kg}$ of a $5 \%$ rat albumin solution in Ringer's lactate was instilled into the right lower lobe. The size of the bacterial inoculum was selected so that blood and liver samples obtained at the conclusion of the experiments were culturepositive in all bacteremic rats. Then, the rats were studied and processed as described above.
Group 3. Effect of amiloride $\left(10^{-3} \mathrm{M}\right)$ pretreatment in rats receiving i.v. $P$. aeruginosa $(n=5)$. Amiloride $\left(10^{-3} \mathrm{M}\right)$, a sodium transport inhibitor, was added to the instillate of bacteremic rats to determine whether the increase in liquid clearance from the distal airspaces in these rats was mediated by an increase in the active uptake of sodium across the alveolar epithelial barrier. Then, the rats were studied and processed as described above. The effect of amiloride in normal rats has already been studied by us (7) and other investigators (17-20). Approximately 30 to $70 \%$ of basal liquid clearance from the distal airspaces is inhibited by $10^{-3} \mathrm{M}$ amiloride.

Group 4. Effect of propranolol $\left(10^{-4}\right.$ or $\left.10^{-5} \mathrm{M}\right)$ pretreatment in rats receiving i.v. P. aeruginosa $(n=7)$. Propranolol $\left(10^{-4} \mathrm{M}\right)(n=4)$ or $\left(10^{-5} \mathrm{M}\right)(n=3)$ was added to the instillate of bacteremic rats to determine whether the increased liquid clearance from the distal airspaces was mediated through stimulation of $\beta$-adrenergic receptors by endogenous catecholamines. Then, the rats were studied and processed as described above. Propranolol has no effect on basal liquid clearance from the distal airspaces in sheep (5), rabbits (16), and rats (7).

Group 5. Effect of continuous i.v. infusion of epinephrine $(n=3)$. To confirm that epinephrine is capable of increasing liquid clearance from the distal airspaces in rats, a continuous i.v. infusion of epinephrine $(0.5 \mu \mathrm{g} / \mathrm{kg} / \mathrm{min})$ was given to non-septic rats. The dose was selected to result in plasma levels of epinephrine comparable with those measured in the bacteremic rats. Then, the rats were studied and processed as described above.

\section{Rabbit studies}

\section{SURGICAL PREPARATION AND VENTILATION}

New Zealand white rabbits $(n=7)$ (range $3-4 \mathrm{~kg}$ ) were anesthetized with pentobarbital $(50 \mathrm{mg} / \mathrm{kg}$ i.v.) and anesthesia was maintained with $5-10 \mathrm{mg} / \mathrm{kg}$ of pentobarbital administered intravenously every $2 \mathrm{~h}$. A right carotid arterial line was inserted to monitor systemic blood pressure and for blood sampling. Pancuronium bromide $(0.3 \mathrm{mg} / \mathrm{kg} / \mathrm{h})$ was given intravenously for neuromuscular blockade. An endotracheal tube was inserted through a tracheostomy. The rabbits were supine and ventilated with a constant-volume pump (Harvard Apparatus, Inc.) with an inspired $\mathrm{O}_{2}$ fraction of 1.0, peak pressures of $12-15 \mathrm{~cm} \mathrm{H}_{2} \mathrm{O}$ and positive endexpiratory pressure of $3 \mathrm{~cm} \mathrm{H}_{2} \mathrm{O}$. The respiratory rate was adjusted to maintain the arterial $\mathrm{PCO}_{2}$ between $35-45 \mathrm{mmHg}$.

\section{PREPARATION OF INSTILLATE}

The preparation of the instillate was similar to that described above for the rat studies, but did not contain the ${ }^{125}$ I-labeled human albumin.

\section{GENERAL PROTOCOL}

For all rabbit studies, we used the following general protocol. After surgery, a 1-h baseline of stable heart rate and blood pressure was required before the instillation of the protein solution into the distal airspaces of the lung. Then, in septic shock studies, one $\mathrm{ml}$ of $10^{9}$ cfu of $P$. aeruginosa (PAO1, Fisher immunotype 7) was administered intravenously over $5 \mathrm{~min}$. In control studies, one $\mathrm{ml}$ of isotonic saline was given over $5 \mathrm{~min}$. Then, the rabbit was placed in the right lateral decubitus position to facilitate liquid deposition into the right lung. Using a $12-\mathrm{ml}$ syringe and a pediatric feeding tube $(5 \mathrm{~F})$, the instillate ( $3 \mathrm{ml} / \mathrm{kg}$ of the $5 \%$ rabbit albumin solution) was delivered into the right lung over $20 \mathrm{~min}$. After $4 \mathrm{~h}$, the abdomen was opened and the rabbits were exsanguinated. The lungs were removed through a midline sternotomy and liquid from the distal airspaces was obtained by passing a pediatric feeding tube $(5 \mathrm{~F})$ into a wedged position in the right lower lobe. After centrifugation, the total protein concentration of the liquid sample was measured.

\section{SPECIFIC PROTOCOLS}

Group 1: Control studies $(n=4)$. After the baseline period, $3 \mathrm{ml} / \mathrm{kg}$ of a 5\% rabbit albumin solution was instilled into the right lung of three rabbits. Also, an additional rabbit was given a continuous infusion of epinephrine at the same dosage as used in the rat experiments $(0.5 \mu \mathrm{g} /$ 
$\mathrm{kg} / \mathrm{min}$ ). The rabbits were studied for $4 \mathrm{~h}$, and then were exsanguinated and processed as described above.

Group 2. Intravenous $P$. aeruginosa studies $(n=3)$. After the baseline period, $10^{9}$ cfu of $P$. aeruginosa (PAO1, Fisher immunotype 7) were administered intravenously over 5 minutes before $3 \mathrm{ml} / \mathrm{kg}$ of a 5\% rabbit albumin solution in Ringer's lactate was instilled into the right lung. Then, the rabbits were studied and processed as described above.

\section{Measurements}

Hemodynamics, pulmonary gas exchange, and protein concentration. Systemic arterial and airway pressures were measured at 30-min intervals. In all experiments, arterial blood gases were measured hourly. Initial and final blood samples as well as samples from instillate and final fluid sample from the distal airspaces were collected to measure total protein concentration with an automated analyzer (AA2 Technicon, Tarrytown, NY).

Lung endothelial and epithelial barrier protein permeability. Two different methods were used to measure the bidirectional flux of albumin across the lung epithelial barrier, as we have done before $(5,16,21$ 25 ). The first method required measurement of residual ${ }^{125} \mathrm{I}$-albumin (the alveolar protein tracer) in the lung as well accumulation of ${ }^{125} \mathrm{I}$ albumin in the plasma. The second method required the measurement of ${ }^{131} \mathrm{I}$-albumin (the vascular protein tracer) in the lungs and the airspaces of the lung.

The total quantity of ${ }^{125} \mathrm{I}$-albumin (the alveolar protein tracer) instilled into the lung was determined by measuring duplicate samples of the instilled solution for total counts ( $\mathrm{cpm} / \mathrm{g}$ ) and then multiplying this data by the total volume instilled into the lung. To calculate the residual ${ }^{125} \mathrm{I}$-albumin in the lung after $4 \mathrm{~h}$, the average radioactivity counts of two 0.5-g samples obtained from the lung homogenate (see below) was multiplied by the total volume of lung homogenate. The ${ }^{125} \mathrm{I}$-albumin in the lung homogenate data was added to the recovered counts in the final aspirate of alveolar fluid to calculate the amount of instilled ${ }^{125} \mathrm{I}$ albumin that remained in the lung after $4 \mathrm{~h}$. The ${ }^{125} \mathrm{I}$-albumin in the circulating plasma was measured from a sample of plasma obtained at the end of the experiment. The plasma fraction was accounted for by multiplying the counts/g times the plasma volume (body weight $\times 0.07$ [1-Hct]).

The second method required measurement of the vascular protein tracer, ${ }^{131} I$-albumin, in the final alveolar sample. The ${ }^{131} I$-albumin counts in the plasma over the course of the experiment were averaged, and the ${ }^{131}$ I-albumin counts in the final airspace samples were expressed as a ratio to the plasma counts. In rat studies, liquid from the distal airspaces $(0.1-0.2 \mathrm{ml})$ was obtained by passing a propylene tube $(0.5 \mathrm{~mm} \mathrm{ID})$ into a wedged position in the right lower lobe. The sample was centrifuged and the radioactivity (counts/gram) of the supernatant were measured. This ratio provided a good index of equilibration of the vascular protein tracer into the airspace compartment, as we and other investigators have shown in other experimental studies of lung epithelial permeability $(5,25,26)$.

Trichloracetic precipitation established that protein tracers in the instillate, liquid from the distal airspaces, and plasma were always more than $98 \%$ protein bound.

Alveolar liquid clearance. The concentration of the instilled rat albumin and the instilled ${ }^{125} \mathrm{I}$-labeled human albumin over $4 \mathrm{~h}$ were used to measure liquid clearance from the distal airspaces, as we have done before $(5,16)$. Because there was no change in lung epithelial permeability to protein in bacteremic rats (see results), this method is accurate to measure liquid clearance from the airspaces of the lung (25). The good correlation in the concentration of albumin the instilled rat albumin and ${ }^{125}$ I-labeled human albumin provides evidence of the reliability of this method (see Table 3 and Fig. 2). The term alveolar does not indicate that all fluid reabsorption occurs at the alveolar level. Some reabsorption may occur across distal bronchial epithelium.

Lung liquid clearance (excess lung water measurement). To determine the extravascular water in the lung after $4 \mathrm{~h}$ in rat studies, standard methods were used, as in our prior studies $(5,22,25,27)$. Before exsanguination, a blood sample was obtained to measure the hemoglobin concentration and the water-to-dry weight ratio of blood for the lung water calculation. Each lung was homogenized separately and the extravascular lung water determined by calculating the water-to-dry weight ratio. Briefly, the volume of the excess extravascular lung water (ELW) of the instilled experimental lung was calculated as the difference between the water-to-dry weight ratios of experimental and contralateral lungs multiplied by the dry weight of the experimental lung. The dry weight of the instilled experimental lung was corrected for the dry weight of the instilled protein remaining in the lung at the end of the experiment. To determine the mass of protein remaining, the dry weight of the instillate was multiplied by the fraction of ${ }^{125} \mathrm{I}$-albumin remaining in the lung. This value was then subtracted from the total dry weight of the experimental lung. The equation is: Excess extravascular lung water $(\mathrm{ml})=[\mathrm{We} /(\mathrm{De}-\mathrm{P})-\mathrm{Wc} / \mathrm{Dc}](\mathrm{De}-\mathrm{P})$ in which $\mathrm{W}$ and $\mathrm{D}$ are extravascular lung water and blood-free dry weight of the experimental lung (e) and the control lung (c), P is the blood-free dry weight of the instilled 5\% rat albumin solution multiplied by the fraction of ${ }^{125} \mathrm{I}$ albumin remaining in the lung after $4 \mathrm{~h}$. This equation does not account for the possibility that some of the circulating plasma may enter the instilled experimental lung. To estimate the quantity of plasma that entered the instilled lung, we measured the transfer of the vascular protein tracer, ${ }^{131}$ I-albumin, into the extravascular spaces of the instilled lung (see above). In addition, changes in the water-to-dry weight ratio of the contralateral (noninstilled) lung caused by the i.v. administration of $P$. aeruginosa were used as an index of lung endothelial injury since the noninstilled lung did not have the confounding presence of the instillation of a protein solution into its air spaces. In preliminary experiments, we found that both lungs gained the same amount of water per gram of tissue over $4 \mathrm{~h}$ from the i.v. administration of $P$. aeruginosa.

Growth and culturing of live P. aeruginosa. P. aeruginosa, Fisher immunotype 7, (PAO1) was used for all these studies. This strain has been described previously (28). These bacteria were maintained in peptone broth containing $25 \%$ glycerol at $-70^{\circ} \mathrm{C}$. Before an experiment, the organisms were transferred to blood agar plates (5\% sheep erythrocytes) for $24 \mathrm{~h}$. Overnight cultures were transferred to fresh medium, tryptone soy broth for another $24 \mathrm{~h}$. On the day of experiment, the bacteria were centrifuged and resuspended to a final concentration of $1.0 \times 10^{8} \mathrm{cfu} / \mathrm{ml}$ (rat studies) or $10^{9} \mathrm{cfu} / \mathrm{ml}$ (rabbit studies) in sterile phosphate buffered saline. Then, the Pseudomonas solution was centrifuged at $1,500 \mathrm{~g}$ for $15 \mathrm{~min}$. The pellet of bacteria was washed twice with phosphate buffered saline, and was resuspended in the same solution.

Before intravascular injection, a sample of bacterial solution was taken for quantitative culture. Samples of blood and lung homogenate were obtained aseptically for culture at the end of the experiments. The concentration of bacteria was then quantified by plating successive 10fold dilutions of the bacterial suspension onto sheep blood agar plates and by scoring visible colonies after $24 \mathrm{~h}$ incubation at $37^{\circ} \mathrm{C}$. The results of these studies showed that $10^{4}-10^{5}$ cfu of $P$. aeruginosa were recovered per gram of lung homogenate, and there was no difference in the concentration of bacteria between both lungs. In addition, the final blood samples as well as the liver samples of bacteremic rats were always culture positive. In contrast, all bacteriological cultures done in control experiments remained negative. All colonies were also subcultured to identify $P$. aeruginosa organisms. Routine biochemical screening and antibiotic sensitivity testing were done to ensure the $P$. aeruginosa strain has not changed between experiments.

Determination of plasma concentrations of epinephrine. In an additional eight rats, $1 \mathrm{ml}$ of blood was collected in a heparinized tube just before, 2 and $4 \mathrm{~h}$ after i.v. administration of $10^{8}$ cfu of $P$. aeruginosa $(n=3)$, Ringer's lactate $(n=2)$ or a continuous i.v. infusion of epinephrine $(0.5 \mu \mathrm{g} / \mathrm{kg} / \mathrm{min})(n=3)$. Also, in the seven rabbits that were studied, the plasma concentrations of epinephrine were determined using the same experimental protocol. Blood samples were immediately centrifuged at $5,000 \mathrm{~g}$ for $5 \mathrm{~min}$ at $4^{\circ} \mathrm{C} ; 0.5 \mathrm{ml}$ of plasma was transferred to an Eppendorf tube and quickly frozen to $-70^{\circ} \mathrm{C}$ in acetone and dry ice. 
Table I. Effect of Intravenous P. aeruginosa on Mean Systemic Arterial Pressure and Arterial pH over $4 h$ in Anesthetized Rats

\begin{tabular}{|c|c|c|c|c|c|}
\hline \multirow{2}{*}{$\begin{array}{l}\text { Experimental } \\
\text { condition }\end{array}$} & \multirow[b]{2}{*}{ No. } & \multicolumn{2}{|c|}{$\begin{array}{c}\text { Mean systemic arterial } \\
\text { pressure }\end{array}$} & \multicolumn{2}{|c|}{ Arterial $\mathbf{p H}$} \\
\hline & & Baseline & Experimental & Baseline & Experimental \\
\hline & & \multicolumn{2}{|c|}{$m m \mathrm{Hg}$} & \multicolumn{2}{|c|}{ units } \\
\hline Controls & 7 & $138 \pm 8$ & $123 \pm 28$ & $7.45 \pm 0.04$ & $7.44 \pm 0.04$ \\
\hline i.v. $P$. aeruginosa & 9 & $122 \pm 14$ & $48 \pm 30 *$ & $7.43 \pm 0.03$ & $7.12 \pm 0.12 *$ \\
\hline
\end{tabular}

Mean \pm SD. $* P<0.05$ vs controls.

Samples were stored at $-70^{\circ} \mathrm{C}$ until analyzed. Plasma was spiked with an internal standard and absorbed on activated alumina at alkaline $\mathrm{pH}$. Epinephrine was eluted by $0.1 \mathrm{M}$ perchloric acid, analyzed by reversephase HPLC using a C8 column, and measured by the amperometric method using an electrochemical detector. Correlation coefficient and detection limit of this method were 0.96 and $10 \mathrm{pg} / \mathrm{ml}$, respectively.

\section{Statistics}

The data are summarized as mean \pm SD. One-way analysis of variance and the Fisher's exact test were used to compare the different rat groups. Unpaired Student's $t$ test was used to compare the two rabbit groups. For the baseline period, data from the last hour of the baseline period was used, but for the experimental period, the data was averaged from the last 30-min time interval of the studies. We regarded a $P$ value of $<0.05$ as statistically significant (29).

\section{Results}

\section{Rat studies}

Effect of i.v. P. aeruginosa. The i.v. administration of high dose $P$. aeruginosa resulted in severe systemic arterial hypotension and metabolic acidosis after $4 \mathrm{~h}$ (Table I). There was no significant change in the $\mathrm{PaO}_{2} / \mathrm{FIO}_{2}$ ratio in bacteremic compared to control rats. The cardiovascular changes were accompanied by the development of mild pulmonary edema as indicated by a $28 \%$ increase in the water-to-dry weight ratio of the non-instilled lung of bacteremic compared with control rats (Fig. 1).

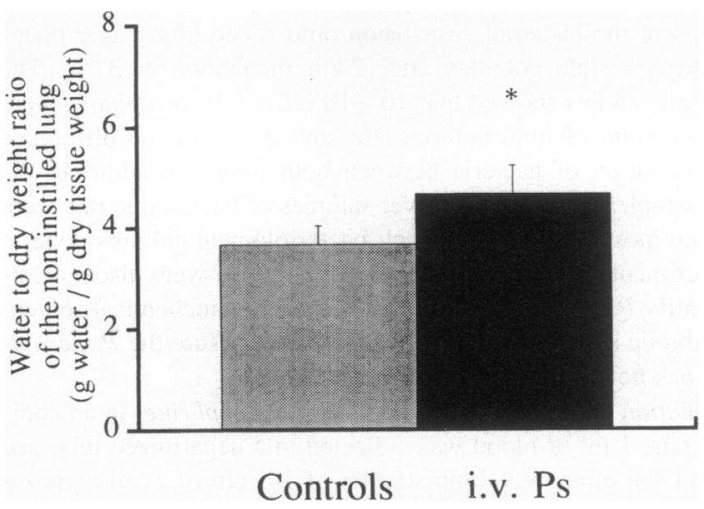

Figure 1. Extravascular water content of the noninstilled (opposite) lung (mean $\pm \mathrm{SD}$ ) is shown for control and bacteremic rats. The extravascular lung water content of the non-instilled lung of bacteremic rats was significantly increased $(P<0.05)$ compared to that measured in controls.
Table II. Effect of Intravenous $P$. aeruginosa on Bidirectional Protein Permeability across the Lung Epithelial Barrier over $4 \mathrm{~h}$ in Anesthetized Rats

\begin{tabular}{lccccc}
\hline & \multicolumn{4}{c}{$\begin{array}{c}\text { Alveolar protein tracer, } \\
\text { 125 I-albumin }\end{array}$} \\
\cline { 3 - 4 } \multicolumn{1}{c}{$\begin{array}{c}\text { Experimental } \\
\text { condition }\end{array}$} & No. & Lung & Blood & $\begin{array}{c}\text { Vascular protein } \\
\text { tracer, }{ }^{131} \mathrm{I} \text {-albumin }\end{array}$ \\
\hline & & \multicolumn{2}{c}{$\%$ of instilled } & Alv fluid/plasma ratio \\
Controls & 7 & $96.7 \pm 3.4$ & $0.6 \pm 0.5$ & $0.08 \pm 0.04$ \\
i.v. P. aeruginosa & 9 & $93.9 \pm 4.5$ & $0.5 \pm 0.3$ & $0.07 \pm 0.03$ \\
\hline
\end{tabular}

Mean \pm SD.

Even though there was a moderate increase in extravascular lung water, a result consistent with the presence of lung endothelial injury and interstitial pulmonary edema, the lung epithelial barrier maintained its relative impermeability to protein since there was no increase in bidirectional protein flux across either the alveolar epithelial barrier (Table II) nor across the pleural space adjacent to the instilled lung (Table III) in bacteremic compared with control rats.

Liquid clearance from the distal airspaces was increased by nearly $100 \%$ in the rats with septic shock compared to the control rats $(74 \pm 15 \%$ septic shock versus $42 \pm 8 \%$ controls, $P$ $<0.01$ ), as reflected by the rise in both the instilled albumin (Table IV) and the alveolar protein tracer ( ${ }^{125} \mathrm{I}$-albumin) concentrations (Fig. 2). There was also a similar increase in the independently measured mean lung liquid clearance in the bacteremic compared to the control rats (Fig. 3).

The accelerated liquid clearance from the distal airspaces as the lung as a whole caused by i.v. $P$. aeruginosa was associated with a greater than 100 -fold increase in the final epinephrine plasma levels measured in bacteremic rats (Fig. 4). In contrast, there was no change in plasma levels of epinephrine in the control rats (Fig. 4).

Effect of amiloride pretreatment. To determine whether the increase in alveolar and lung liquid clearance in bacteremic rats was dependent on an increase in the sodium uptake by lung epithelial cells, amiloride $\left(10^{-3} \mathrm{M}\right)$ was added to the albumin solution instilled into the air spaces of bacteremic rats. Amiloride completely prevented the increase in liquid clearance from the distal airspaces found in the bacteremic rats; the increase in the instilled albumin (Table IV) and the alveolar protein

Table III. Effect of Intravenous $P$. aeruginosa on the Accumulation of Alveolar ( ${ }^{125}$ I-albumin) and Vascular $\left({ }^{131} I-\right.$ albumin) Protein Tracers and Liquid in the Pleural Space Adjacent to the Instilled Lung over $4 h$ in Anesthetized Rats

\begin{tabular}{lcccc}
\hline $\begin{array}{c}\text { Experimental } \\
\text { condition }\end{array}$ & No. & $\begin{array}{c}\text { Alveolar } \\
\text { protein tracer, } \\
{ }^{125} \text { I-albumin }\end{array}$ & $\begin{array}{c}\text { Pleural fluid/plasma } \\
\text { 131-albumin ratio }\end{array}$ & $\begin{array}{c}\text { Volume of } \\
\text { pleural } \\
\text { effusion }\end{array}$ \\
\hline & & \% of instilled & & $m l$ \\
Controls & 7 & $0.04 \pm 0.02$ & $0.11 \pm 0.04$ & $0.2 \pm 0.2$ \\
i.v. P. aeruginosa & 9 & $0.05 \pm 0.05$ & $0.15 \pm 0.05$ & $0.2 \pm 0.1$ \\
\hline
\end{tabular}

Mean $\pm S D$. 
Table IV. Effect of Alveolar Instillation of Amiloride $\left(10^{-3} \mathrm{M}\right)$, or Propranolol $\left(10^{-4}\right.$ or $\left.10^{-5} \mathrm{M}\right)$ on Protein Concentration of the Fluid Obtained from the Distal Airspaces of the Lung in Anesthetized Rats Given i.v. P. aeruginosa

\begin{tabular}{|c|c|c|c|}
\hline \multirow[b]{2}{*}{ Experimental condition } & \multirow[b]{2}{*}{ No. } & \multicolumn{2}{|c|}{$\begin{array}{l}\text { Alveolar protein } \\
\text { concentration }\end{array}$} \\
\hline & & Initial & Final \\
\hline & & \multicolumn{2}{|c|}{$\mathrm{g} / 100 \mathrm{~mol}$} \\
\hline Controls & 7 & $4.5 \pm 0.8$ & $7.1 \pm 1.1$ \\
\hline i.v. $P$. aeruginosa & 9 & $4.6 \pm 0.8$ & $17.6 \pm 6.5^{*}$ \\
\hline i.v. $P$. aeruginosa + amiloride $\left(10^{-3} \mathrm{M}\right)$ & 5 & $4.6 \pm 0.8$ & $6.7 \pm 0.9^{\ddagger}$ \\
\hline i.v. $P$. aeruginosa + propranolol $\left(10^{-4} \mathrm{M}\right)$ & 4 & $4.5 \pm 0.1$ & $7.1 \pm 0.5^{\ddagger}$ \\
\hline i.v. $P$. aeruginosa + propranolol $\left(10^{-5} \mathrm{M}\right)$ & 3 & $4.6 \pm 0.1$ & $8.4 \pm 0.3^{\ddagger}$ \\
\hline
\end{tabular}

Mean \pm SD. $\quad{ }^{*} P<0.05$ vs controls; ${ }^{\ddagger} P<0.05$ vs i.v. $P$. aeruginosa rats.

concentrations (Fig. 2) were similar to studies in control, nonseptic rats. In addition, this effect of amiloride on liquid transport across the lung epithelium was confirmed by the measurement of lung liquid clearance (Fig. 3).

Effect of $\beta$-adrenergic antagonist pretreatment. Since the increased liquid clearance from the distal airspaces in bacteremic rats was dependent on an increase in sodium uptake by lung epithelial cells, we tested the hypothesis that the effect was mediated by stimulation of $\beta$-adrenergic receptors on the plasma membrane of lung epithelial cells by adding propranolol

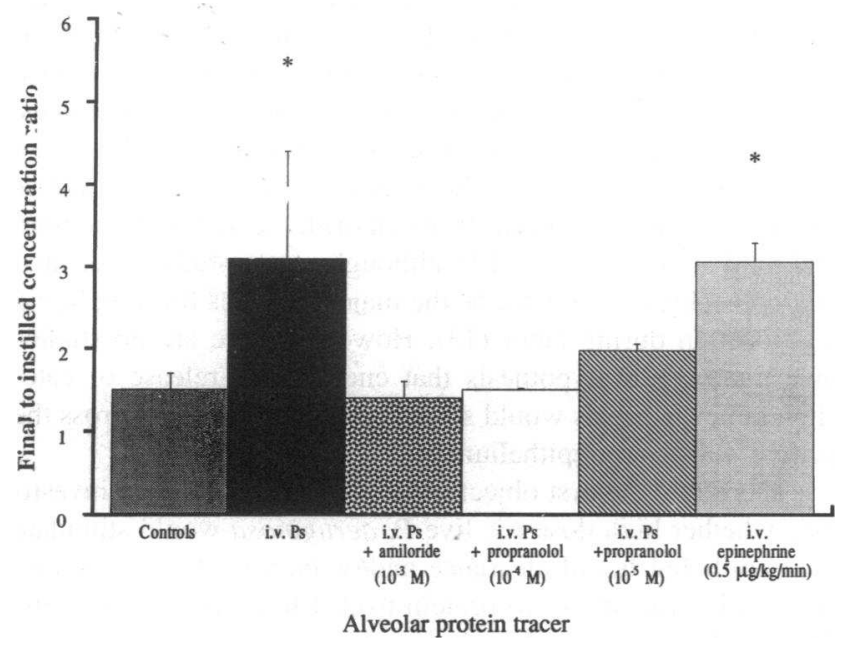

Figure 2. Final to instilled concentration ratio of the alveolar protein tracer ( ${ }^{125} \mathrm{I}$-albumin) (mean $\left.\pm \mathrm{SD}\right)$ is shown for controls, rats receiving i.v. $P$. aeruginosa, bacteremic rats pretreated with either amiloride $\left(10^{-3}\right.$ M) or propranolol $\left(10^{-4}\right.$ or $\left.10^{-5} \mathrm{M}\right)$ added to the alveolar instillate, and for nonbacteremic rats receiving a continuous i.v. infusion of epinephrine. The pretreatment of bacteremic rats with either amiloride or propranolol prevented the significant increase in the final to instilled concentration ratio of the alveolar protein tracer caused by i.v. $P$. aeruginosa compared with controls. The administration of a continuous i.v. infusion of $0.5 \mu \mathrm{g} / \mathrm{kg} / \mathrm{min}$ of epinephrine over $4 \mathrm{~h}$ achieved comparable plasma levels of epinephrine to those measured in bacteremic rats, and resulted in a similar increase in the final to instilled concentration ratio of the alveolar protein tracer to that observed in bacteremic rats.

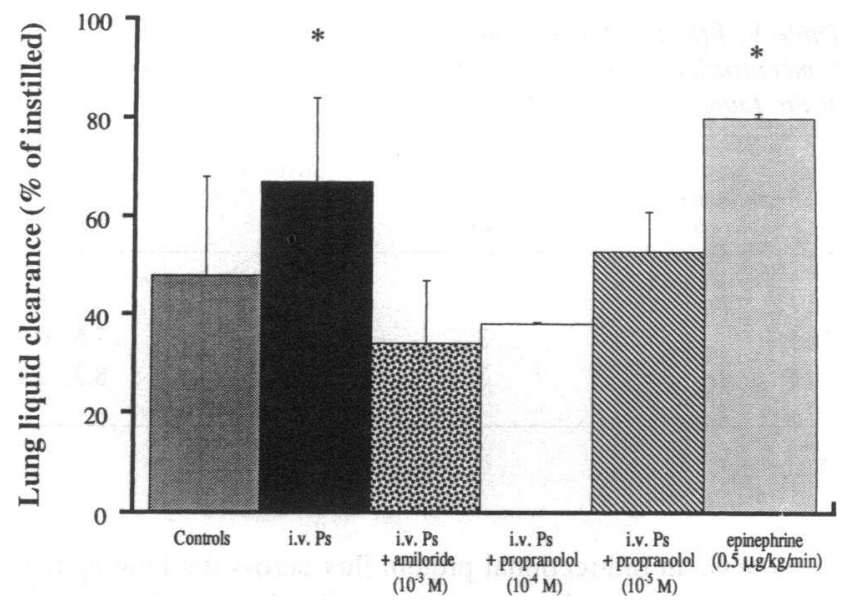

Figure 3. Lung liquid clearance (percent of instilled liquid) (mean \pm SD) is shown for controls, rats receiving i.v. $P$. aeruginosa, bacteremic rats pretreated with either amiloride $\left(10^{-3} \mathrm{M}\right)$ or propranolol $\left(10^{-4}\right.$ or $10^{-5}$ $\mathrm{M})$ added to the alveolar instillate, and for nonbacteremic rats receiving a continuous i.v. infusion of epinephrine. The pretreatment of bacteremic rats with either amiloride or propranolol prevented the accelerated lung liquid clearance caused by the i.v. administration of high dose $P$. aeruginosa. The administration of a continuous i.v. infusion of $0.5 \mu \mathrm{g} / \mathrm{kg} / \mathrm{min}$ of epinephrine over $4 \mathrm{~h}$ which achieved comparable plasma levels of epinephrine to those measured in bacteremic rats, and resulted in a similar increase in lung liquid clearance to the bacteremic rats.

$\left(10^{-4}\right.$ or $\left.10^{-5} \mathrm{M}\right)$ to the instillate of additional rats receiving i.v. $P$. aeruginosa. Propranolol $\left(10^{-4}\right.$ or $\left.10^{-5} \mathrm{M}\right)$, in a dosedependent manner, prevented the increase in the liquid clearance from the distal airspaces in bacteremic rats (Table IV, Fig. 2). Similar results were obtained for lung liquid clearance (Fig. 3). Finally, in the amiloride and propranolol experiments, there was

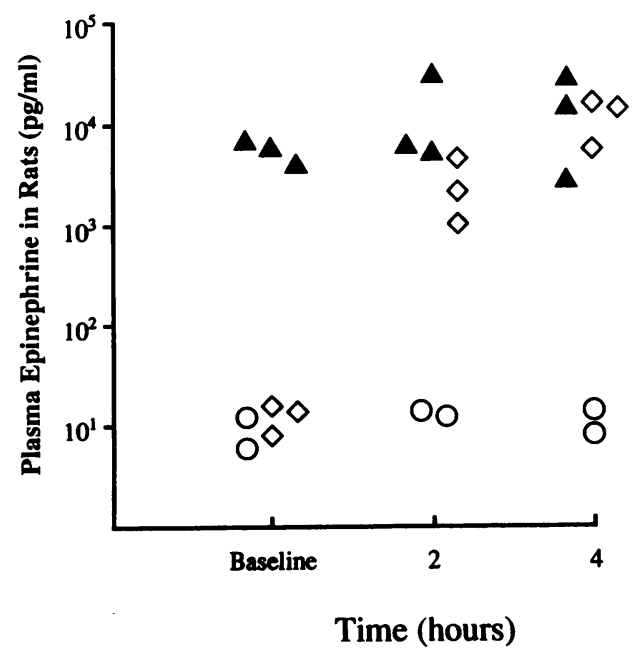

Figure 4. Individual plasma levels of epinephrine in control rats $(n=2$, ○), bacteremic rats $(n=3, \diamond)$ and in nonbacteremic rats receiving a continuous i.v. infusion of epinephrine over $4 \mathrm{~h}(n=3, \Delta)$. The i.v. administration of high dose $P$. aeruginosa caused a more than 100 -fold increase in endogenous plasma levels of epinephrine over $4 \mathrm{~h}$ in anesthetized rats. Similar plasma levels of epinephrine were achieved by a continuous exogenous i.v. administration of $0.5 \mu \mathrm{g} / \mathrm{kg} / \mathrm{min}$ of epinephrine. 
Table V. Effect of Intravenous $P$. aeruginosa on Protein Concentration of the Fluid Obtained from the Distal Airspaces of the Lung over $4 h$ in Anesthetized Rabbits

\begin{tabular}{llll}
\hline \multirow{2}{*}{$\begin{array}{c}\text { Experimental } \\
\text { condition }\end{array}$} & No. & \multicolumn{2}{c}{ Alveolar protein concentration } \\
\cline { 3 - 4 } & & Initial & Final \\
\hline & 3 & & \\
Control & 3 & $4.1 \pm 00 \mathrm{ml}$ & \\
i.v. $P$. aeruginosa & & $4.4 \pm 0.3$ & $8.5 \pm 0.9$ \\
\hline
\end{tabular}

Mean \pm SD.

no increase in bidirectional protein flux across the lung epithelial barrier compared to controls, and the decrease in systemic arterial pressure and in blood arterial $\mathrm{pH}$ was comparable with the data in the bacteremic rats instilled with a protein solution alone.

Effect of epinephrine infusion. To confirm that epinephrine can stimulate liquid clearance from the distal airspaces, a continuous i.v. infusion of epinephrine $(0.5 \mu \mathrm{g} / \mathrm{kg} / \mathrm{min})$ was administered to nonseptic rats, resulting in plasma levels comparable to those measured in the bacteremic rats (Fig. 4). This dose of epinephrine caused a significant increase in the liquid clearance from the distal airspaces, as demonstrated by an increase in the instilled to final rat albumin (from $4.6 \pm 0.2$ to $13.7 \pm 2.0 \mathrm{~g} / 100$ $\mathrm{ml}, P<0.05$ ) and alveolar protein tracer concentrations (Fig. 2) compared with those measured in control rats (Table IV, Fig. 2). Similar results were obtained for the lung liquid clearance (i.v. epinephrine: $79.8 \pm 0.7 \%$ versus controls: $47.5 \pm 19.6 \%, P$ $<0.05)$. Therefore, the continuous i.v. infusion of epinephrine resulted in the same increase in liquid clearance from the distal airspaces as observed in bacteremic rats.

\section{Rabbit studies}

To provide additional confirmation that the results of the rat experiments depended on $\beta$-adrenergic agonist stimulation of liquid clearance from the distal airspaces, i.v. $P$. aeruginosa $\left(10^{9} \mathrm{cfu}\right)$ was administered to rabbits, a species which has been shown to be insensitive to the stimulating effect of exogenous $\beta$-adrenergic agonists on liquid transport across the lung epithelium $(15,16)$. As observed in the bacteremic rats, high dose i.v. $P$. aeruginosa resulted in systemic arterial hypotension $(30 \pm 5 \mathrm{~mm} \mathrm{Hg}$ septic shock versus $93 \pm 8 \mathrm{~mm} \mathrm{Hg}$ controls, $P$ $<0.05)$ and metabolic acidosis $(7.10 \pm 0.06$ septic shock vs $7.46 \pm 0.03$ controls, $P<0.05$ ). However, in contrast to the rat studies, i.v. $P$. aeruginosa did not increase liquid clearance from the distal airspaces in bacteremic compared with control rabbits ( $50 \%$ of the liquid was cleared). There was no increase in the instilled to final rabbit albumin concentration in bacteremic compared to control non-septic rabbits (Table V), even though the plasma levels of epinephrine measured in these experiments (Fig. 5) were comparable to those in bacteremic rats (Fig. 4). One nonbacteremic rabbit was given a high dose of epinephrine $(0.5 \mu \mathrm{g} / \mathrm{kg} / \mathrm{min}$ ) (Fig. 5), and there was no increase in the instilled to final rabbit albumin concentration compared to the controls.

\section{Discussion}

The overall objective of these experiments was to test the hypothesis that the endogenous release of catecholamines associ-

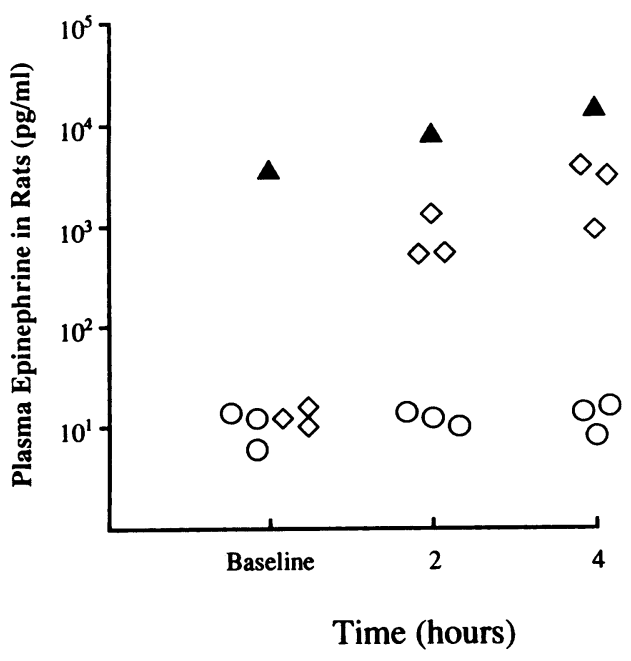

Figure 5. Individual plasma levels of epinephrine in control rabbits ( $n$ $=3, \bigcirc)$, bacteremic rabbits $(n=3, \diamond)$, and in one non-bacteremic rabbit given a continuous i.v. infusion of epinephrine over $4 \mathrm{~h}(\boldsymbol{\Delta})$. The i.v. administration of high dose $P$. aeruginosa caused a more than 100 -fold increase in the plasma levels of epinephrine over $4 \mathrm{~h}$ in anesthetized rabbits.

ated with the development of septic shock would stimulate the removal of excess fluid from the distal airspaces of the lung. We and other investigators have previously reported that the exogenous administration of $\beta$-adrenergic agonists stimulates active transport of sodium across the epithelial barrier of the lung in vivo in several species (5-7) as well as in perfused rat lung models $(3,4)$. Rabbits, however, do not increase fluid clearance from the distal airspaces of the lung in the presence of $\beta$-adrenergic stimulation $(15,16)$. In other animal studies, endogenous release of catecholamines during labor has been associated with reversal of the direction of volume flow across the lung epithelial barrier from chloride secretion to sodium and fluid absorption $(11-12)$, although recent studies indicated that epinephrine might not be the major stimulus for lung liquid reabsorption during labor (13). However, there are no studies investigating the hypothesis that endogenous release of catecholamines in sepsis would stimulate liquid transport across the mature pulmonary epithelium.

Therefore, the first objective of these studies was to investigate whether high dose i.v. live $P$. aeruginosa would stimulate lung epithelial liquid clearance and/or increase the pulmonary epithelial permeability to protein over $4 \mathrm{~h}$ in anesthetized rats. The results indicated that there was no increase in the lung epithelial permeability to protein in bacteremic compared to control rats, despite the development of systemic hypotension, metabolic acidosis and mild pulmonary edema (Table I and Fig. 1). The mild pulmonary edema is consistent with the lung endothelial injury and interstitial pulmonary edema reported in prior studies in which i.v. $P$. aeruginosa was given to sheep (30). Since the lung epithelium maintained its relative impermeability to protein in the bacteremic rats, we were able to use the increase in the instilled albumin concentration as a reliable estimate of the liquid clearance from the distal airspaces of the lung, as we have done before $(5-7,16,21,22)$. Measurements of the alveolar protein concentration indicated that there was a 
nearly $100 \%$ increase in the transport of liquid across the lung epithelial barrier, which was associated with more than a 100fold increase in plasma levels of epinephrine (Table IV, Fig. 4). These results were confirmed by comparable changes in the instilled alveolar protein tracer $\left({ }^{125} \mathrm{I}\right.$-albumin) concentration (Fig. 2), and in the independently measured lung liquid clearance (Fig. 3).

There are two major discoveries in these studies. First, the preservation of an intact lung epithelial barrier in pathological conditions appears to be essential for efficient liquid clearance from the distal airspaces, as others have suggested $(31,32)$. This is supported by our previous observation that resolution of pulmonary edema occurred faster in patients with acute lung injury who had an increase in alveolar edema fluid protein concentration during the first $12 \mathrm{~h}$ after alveolar flooding compared with those who did not (33). In fact, the alveolar and lung epithelium appear to be more resistant to injury than the lung endothelium. For example, we reported that clearance of excess protein and liquid from the distal airspaces was not affected by high doses of alveolar and/or i.v. endotoxin (25) nor by the absence of blood flow or mechanical ventilation for several hours in sheep (34). However, when the lung epithelial barrier was injured by the instillation of live $P$. aeruginos $a$ into the airspaces of sheep (25), or rabbits (35), the increase in the lung epithelial permeability to protein was always associated with a decreased rate of transport of liquid across this barrier. In the present studies, we have used labeled albumin to quantify bidirectional changes in lung epithelial permeability. The data indicate that there was no increase in the bidirectional movement of albumin across the pulmonary epithelium (Table II) or the pleural mesothelium (Table III) in bacteremic compared to control rats (Table II).

Second, the present studies are the first demonstration that septic shock can stimulate transport of fluid across the lung epithelium. What mechanism is responsible for the increased liquid clearance from the distal airspaces observed in this model of sepsis in rats? This effect was not caused by a difference in the surface area instilled in bacteremic compared with control rats. First, the Evans blue dye added to the instilled albumin solution confirmed that the instillation was always done in the lower lobe of the right lung. Second, the coefficient of variation of the instilled rat albumin concentration measured at the conclusion of the control experiments was only $15 \%$ (Table IV), whereas there was a nearly $150 \%$ increase in the final instilled rat albumin concentration measured in the bacteremic compared to control rats $(17.6 \pm 6.5$ vs $7.1 \pm 1.1 \mathrm{~g} / 100 \mathrm{ml})$. Finally, we have previously reported that the liquid clearance rates from the distal airspaces were comparable after the instillation of 2 or $3 \mathrm{ml} / \mathrm{kg}$ of autologous serum into the airspaces of non-septic anesthetized ventilated rabbits (16). Thus, we hypothesized that the endogenous release of catecholamines induced by high dose i.v. $P$. aeruginosa may be responsible for the increased transport of fluid across the lung and alveolar epithelium.

Therefore, the second and third objectives of these studies were to explore the mechanisms of this accelerated liquid clearance from the distal airspaces by adding either amiloride, a sodium transport inhibitor, or propranolol, a $\beta$-adrenergic antagonist, to the protein solution instilled into the distal airspaces of bacteremic rats. Amiloride decreased liquid clearance from the distal airspaces to a value that was less than but not statistically different from controls (Table IV, Fig. 2). Similar results were obtained for lung liquid clearance (Fig. 3). In the present studies, $10^{-3} \mathrm{M}$ amiloride was added to the instillate, but because amiloride is $50 \%$ bound to protein (36), the effective concentration of amiloride was $5 \times 10^{-4} \mathrm{M}$. These results are in accordance with previous studies which have reported that amiloride reduced the basal rate of active sodium transport across the pulmonary epithelium by $30-70 \%$ in isolated rat lungs (17-20), as well as in rat, rabbit and sheep lungs in vivo $(5,7,16)$. In addition, amiloride $\left(10^{-3}\right.$ or $\left.10^{-4} \mathrm{M}\right)$ blocked almost completely $(90 \%)$ the stimulation of liquid transport across the lung and alveolar epithelium induced by exogenous $\beta$-adrenergic agonist in anesthetized sheep (5) and in isolated perfused rat lungs (3), as well as the epinephrine-induced reabsorption of fluid of the distal airspaces in mature fetal lung (37). The mechanisms for the amiloride effect at these concentrations may include an inhibitory effect on conductive sodium channels on the apical surface of alveolar epithelial cells and/or an effect on the $\mathrm{Na}^{+}-\mathrm{H}^{+}$antiport system (36). However, the response to $\beta$-adrenergic stimulation probably does not occur as the result of $\mathrm{Na}^{+}-\mathrm{H}^{+}$exchange stimulation because $\beta$-adrenergic agonists do not change the intracellular $\mathrm{pH}$ in alveolar type II cells (38). Thus, our results indicate that the increased transport of fluid across the lung epithelium in bacteremic rats depends on sodium-dependent uptake by epithelial cells, an effect that probably depends on an increase in intracellular cAMP concentration.

After we established that the increased liquid clearance from the distal airspaces in bacteremic rats was dependent on an increase in sodium-dependent uptake by lung epithelial cells, we tested the hypothesis that the catecholamine effect was mediated by stimulation of $\beta$-adrenergic receptors. We had previously reported that the increase in liquid clearance from the distal airspaces caused by the i.v. administration of $\beta$-adrenergic agonists in sheep was not dependent on changes in pulmonary hemodynamics, pulmonary blood flow, lung lymph flow or alveolar surface area, but was mediated through the activation of $\beta$ receptors (5). In the present studies, propranolol $\left(10^{-4}\right.$ or $10^{-5}$ M) was added to the instillate of bacteremic rats; propranolol prevented the increase in liquid clearance from the distal airspaces caused by i.v. $P$. aeruginosa (Table IV, Fig. 2). Similar results were obtained for lung liquid clearance (Fig. 3).

These results deserve several comments. First, $\beta$-adrenergic receptors have been shown to be abundantly present in alveolar walls of rat and human lungs $(39,40)$, as well in membranes of freshly isolated alveolar epithelial type II cells (41). In addition, immunohistochemical analysis has revealed that these $\beta$-adrenergic receptors are functional, since they respond to a $\beta$-adrenergic agonist with a rise in cAMP (42). Second, we have previously reported that $\beta$-adrenergic antagonists do not affect basal liquid clearance across the lung epithelium in normal anesthetized sheep (5), dogs (6), or rats (7). Also, in isolated alveolar type II cells, the presence of propranolol alone did not decrease the basal number of domes formed (1). In the present studies, a racemic mixture of propranolol was used at two different concentrations $\left(10^{-4}\right.$ and $\left.10^{-5} \mathrm{M}\right)$. Since the $(-)$ enantiomer of propranolol is the active form of the drug, and that propranolol is highly bound to protein (90-95\%), the effective concentrations of propranolol used in bacteremic rats were in fact much lower ( $5 \times 10^{-6}$ and $5 \times 10^{-7} \mathrm{M}$, respectively), excluding an effect of propranolol independent of $\beta$-adrenergic blockade (43). Finally, we have previously reported that pretreatment with propranolol instilled into the distal airspaces of the lung 
at concentrations comparable to the present studies, almost completely blocked the effect of exogenous $\beta$-adrenergic agonist therapy on lung liquid clearance in sheep (5). Thus, our results indicate that the increased transport of fluid across the lung epithelium in bacteremic rats depends on sodium-facilitated transport out of the airspaces, an effect mediated through the stimulation of $\beta$-adrenergic receptors situated in the alveolar walls of the lung. Interestingly, $\beta$-adrenergic agonists appear equally effective when given in the airspaces or in the circulating plasma, suggesting that receptors may be present on both sides of the epithelium $(3,5)$.

The fourth objective of these studies was to reproduce the effect of augmented liquid clearance from the distal airspaces in bacteremic rats by administering to nonseptic rats a continuous infusion of epinephrine that would result in plasma levels of epinephrine comparable to the levels measured in the bacteremic rats (Fig. 4). We specifically examined the role of epinephrine since this hormone is entirely derived from the adrenal medulla and, in contrast to norepinephrine, functions as a circulating hormone. In addition, the $\beta_{2}$-adrenergic receptors, the most abundant in the alveoli (ratio $\beta_{2}-\beta_{1}: 3$ to 1 ) (40), are regulated by epinephrine while the $\beta_{1}$ receptors are under the control of norepinephrine (44). The administration of $0.5 \mu \mathrm{g} /$ $\mathrm{kg} / \mathrm{min}$ of epinephrine over $4 \mathrm{~h}$ caused a significant increase in the instilled rat albumin and protein tracer ( ${ }^{125} \mathrm{I}$-albumin) concentrations comparable with the values measured in bacteremic rats (Table IV, Fig. 2). Also, similar results were obtained for lung liquid clearance. These data are in accordance with the results of our previous study in which we reported that i.v. terbutaline, administered at a comparable infusion rate $(0.6 \mu \mathrm{g} /$ $\mathrm{kg} / \mathrm{min}$ ), stimulated the transport of liquid across the lung epithelial barrier in anesthetized sheep (5).

High plasma levels of catecholamines may lead to desensitization of the tissue response to $\beta$-adrenergic agonists by uncoupling, sequestration, or absolute decrease in the number of $\beta$ adrenergic receptors (45). However, this issue has been investigated by Liggett et al. (46) who have reported that the shortterm activation of sympathochromaffin system of patients undergoing thoracotomy did not cause a significant sequestration of cell surface $\beta$-adrenergic receptors on circulating mononuclear leukocytes and on alveolar epithelial cells. In addition, epinephrine concentrations comparable to those measured in our bacteremic rats only produced a modest degree (20-30\%) of internalization of $\beta$-adrenergic receptors on mononuclear leukocytes in vitro (47).

The final objective of these studies was to confirm the results of the rat experiments by examining the effect of i.v. $P$. aeruginosa on the transport of liquid across the lung and alveolar epithelium in rabbits, a species known to be insensitive to the stimulating effect of exogenous $\beta$-adrenergic agonists on liquid transport across the pulmonary epithelium $(15,16)$. Intravenous $P$. aeruginosa caused the development of septic shock associated with increased plasma levels of epinephrine comparable to those measured in bacteremic rats (Fig. 5). However, there was no increase in the liquid clearance from the distal airspaces in bacteremic compared with control rabbits (Table V). Rabbits have been shown to have $\beta$-adrenergic receptors in the alveolar walls of the lung (48). Also, these receptors are functional since the i.v. administration of $\beta$-adrenergic agonists caused a rapid increase in the secretion rate of phosphatidylcholine in fetal rabbit lung in vivo (49), an effect blocked by $\beta$-adrenergic antagonists (50). However, although there was a decrease in the extravascular water lung content after vaginal delivery in newborn rabbits, $\beta$-adrenergic antagonists did not cause a significant change in lung water content either at or after birth, regardless the route of delivery (50). These results indicate that, in contrast to other mammals (including humans), another control system is more important than the sympathetic system in regulating lung water clearance at this stage of development in the rabbit.

Our studies of experimental septic shock have important implications for septic shock in man. For instance, the endogenous release of catecholamines may have a role in minimizing the accumulation of alveolar edema during the early phase of sepsis in humans, particularly if there is minimal or no injury to the alveolar epithelial barrier. Interestingly, only one third of patients with septic shock develop clinical evidence of alveolar flooding (51).

In summary, the results of these studies demonstrate that the endogenous release of catecholamines associated with early septic shock stimulates fluid clearance across the pulmonary epithelium. This effect is mediated through $\beta$-adrenergic receptors, and it depends on an augmented uptake of sodium by lung epithelial cells. Since our recent study indicated that $\beta$ adrenergic agonist therapy stimulated epithelial liquid clearance in the isolated human lung (8), the findings of this study strongly suggest that the endogenous release of epinephrine in human septic shock or in other pathological conditions, such as cardiogenic or traumatic shock, may result in an increase in the capacity of the lung epithelial barrier to remove excess alveolar fluid, a novel previously unrecognized mechanism promoting the clearance of alveolar edema.

\section{Acknowledgments}

The authors thank Oscar Osorio, Richard Shanks, Michael Grady, and Paul Sumner for their technical assistance in carrying out these studies.

This work was primarily supported by National Heart, Lung and Blood Institute Grants HL19155, HL 28516, and HL51854. Dr. Pittet was supported by a Fellowship from the Swiss National Science Foundation and a Fellowship from the Surgical Infection Society-Europe.

\section{References}

1. Goodman, B. E., S. E. S. Brown, and E. D. Crandall. 1984. Regulation of transport across pulmonary alveolar epithelial cell monolayers. J. Appl. Physiol. 57:703-710.

2. Mason, R. J., M. C. Williams, J. H. Widdicombe, M. F. Sanders, D. S. Misfeldt, and L. C. Berry. 1982. Transepithelial transport by pulmonary alveolar type II cells in primary culture. Proc. Natl. Acad. Sci. USA. 79:6033-6037.

3. Crandall, E. D., T. H. Heming, R. L. Palombo, and B. E. Goodman. 1986. Effect of terbutaline on sodium transport in isolated perfused rat lung. J. Appl. Physiol. 60:289-294.

4. Saumon, G., G. Basset, F. Bouchonnet, and C. Crone. 1987. cAMP and $\beta$ adrenergic stimulation of rat alveolar epithelium. Effects on fluid absorption and paracellular permeability. Pfluegers Arch. Eur. J. Physiol. 410:464-470.

5. Berthiaume, Y., N. C. Staub, and M. A. Matthay. 1987. Beta-adrenergic agonists increase lung liquid clearance from the alveoli of anesthetized sheop. $J$. Clin. Invest. 79:335-343.

6. Berthiaume, Y., V. C. Broaddus, M. A. Gropper, T. Tanita, and M. A. Matthay. 1988. Alveolar liquid and protein clearance from normal dog lungs. $J$. Appl. Physiol. 65:585-593.

7. Jay, R. C., C. Garat, M. Meignan, J. F. Pittet, M. Zelter, and M. A. Matthay. 1994. Alveolar liquid and protein clearance in anesthetized, ventilated rats. $J$. Appl. Physiol. 76:2636-2642.

8. Sakuma, T., G. Okinawa, T. Nakada, T. Nishimura, S. Fujimura, and M. A. 
Matthay. 1994. Alveolar fluid clearance in the resected human lung. Am. J. Respir. Crit. Care Med. In press.

9. Cott, G. R., K. Suguhara, and R. J. Mason. 1986. Stimulation of net active ion transport across alveolar type II cell monolayers. Am. J. Physiol. 250:C222C227.

10. Matalon, S. 1991. Mechanisms and regulation of ion transport in adult mammalian alveolar type II cells. Am. J. Physiol. 261:C727-C738.

11. Brown, M. J., R. E. Olver, C. A. Ramsden, L. B. Strang, and D. V. Walters. 1983. Effects of adrenaline and of spontaneous labour on the secretion and absorption of lung liquid in the fetal lamb. J. Physiol. (Lond.). 344:137-152.

12. O'Brodovich, H. 1991. Epithelial ion transport in the fetal and perinatal lung. Am. J. Physiol. 261:C555-C564.

13. Chapman, D. L., D. P. Carlton, D. W. Nielson, J. J. Cummings, F. R. Poulain, and R. D. Bland. 1994. Changes in lung liquid during spontaneous labor in fetal sheep. J. Appl. Physiol. 76:523-530.

14. Baue, A. E., B. Gunther, W. Hartl, M. Ackenheil, and G. Heberer. 1984. Altered hormonal activity in severely ill patients after injury or sepsis. Arch. Surg. 119:1125-1132.

15. Effros, R. M., G. R. Mason, J. Hukkanen, and P. Silverman. 1987. Reabsortion of solute and water from fluid-filled rabbit lungs. Am. Rev. Respir. Dis. 136:669-676.

16. Smedira, N., L. Gates, R. Hastings, C. Jayr, T. Sakuma, J. F. Pittet, and M. A. Matthay. 1991. Alveolar and lung liquid clearance in anesthetized rabbits. J. Appl. Physiol. 70:1827-1835.

17. Basset, G., C. Crone, and G. Saumon. 1987. Significance of active ion transport in transalveolar water absorption: a study on isolated rat lung. J. Physiol. (Lond.). 384:311-324.

18. Effros, R. M., G. R. Mason, J. Hukkanen, and P. Silverman. 1988. New evidence for active sodium transport from fluid-filled rat lungs. J. Appl. Physiol. 66:906-919.

19. Basset, G., C. Crone, and G. Saumon. 1987. Fluid absorption by rat lung in situ: pathways for sodium entry in the luminal membrane of alveolar epithelium. J. Physiol. (Lond.). 384:325-345.

20. Goodman, B. E., K. J. Kim, and E. D. Crandall. 1987. Evidence for active sodium transport across alveolar epithelium of isolated rat lung. J. Appl. Physiol. 62:2460-2466.

21. Matthay, M. A., C. Landolt, and N. C. Staub. 1982. Differential liquid and protein clearance from the alveoli of anesthetized sheep. J. Appl. Physiol. 53:96-104.

22. Matthay, M. A., Y. Berthiaume, and N. C. Staub. 1985. Long term clearance of liquid and protein from the lungs of unanesthetized sheep. J. Appl. Physiol. 59:928-934.

23. Berthiaume, Y., K. Albertine, M. Grady, G. Fick, and M. A. Matthay. 1989. Protein clearance from the air spaces and lungs of unanesthetized sheep over 144 hours. J. Appl. Physiol. 67:1887-1897.

24. Jayr, C., and M. A. Matthay. 1991. Alveolar and lung liquid clearance in the absence of pulmonary blood flow in sheep. J. Appl. Physiol. 71:1679-1687.

25. Wiener-Kronish, J. P., K. H. Albertine, and M. A. Matthay. 1991. Differential responses of the endothelial and epithelial barriers of the lung in sheep to $\mathrm{E}$. coli endotoxin. J. Clin. Invest. 88:864-875.

26. Nelson, R. M., B. R. McIntyre, and E. A. Egan. 1978. Solute permeability of the alveolar epithelium in alloxan edema in dogs. J. Appl. Physiol. 44:353357.

27. Selinger, S. L., R. D. Bland, R. H. Demling, and N. C. Staub. 1975. Distribution volume of ${ }^{131} \mathrm{I}$-albumin, ${ }^{14} \mathrm{C}$-sucrose and ${ }^{36} \mathrm{Cl}$ in sheep. J. Appl. Physiol. 39:773-779.

28. Holloway, B. W., V. Krishnapillae, and A. F. Morgan. 1979. Chromosomal genetics of Pseudomonas. Microbiol. Rev. 43:73-102. NJ.

29. Zar, J. H. 1974. Biostatistical Analýsis. Prentice Hall, Englewood Cliffs,

30. Brigham, K., W. C. Woolverton, C. H. Blake, and N. C. Staub. 1974. Increased sheep lung vascular permeability caused by Pseudomonas bacteriemia. J. Clin. Invest. 54:792-804.

31. Holter, J. F., J. E. Weiland, E. R. Pacht, J. E. Gadek, and W. B. Davis.
1986. Protein permeability in the adult respiratory distress syndrome. Loss of size selectivity of the alveolar epithelium. J. Clin. Invest. 78:1513-1522.

32. Saumon, G., and G. Basset. 1993. Electrolyte and fluid transport across the mature alveolar epithelium. J. Appl. Physiol. 74:1-15.

33. Matthay, M. A., and J. P. Wiener-Kronish. 1990. Intact epithelial barrier function is critical for the resolution of alveolar edema in humans. Am. Rev. Respir. Dis. 142:1250-1257.

34. Sakuma, T., J. F. Pittet, C. Jayr, and M. A. Matthay. 1993. Alveolar liquid and protein clearance in the absence of blood flow or ventilation in sheep. $J$. Appl. Physiol. 74:176-185.

35. Wiener-Kronish, J. P., T. Sakuma, I. Kudoh, J. F. Pittet, D. Frank, L. Dobbs, M. Vasil, and M. A. Matthay. 1993. Alveolar epithelial injury and pleural empyema in acute $P$. aeruginosa pneumonia in anesthetized rabbits. J. Appl. Physiol. 75:1661-1669.

36. Garty, H., and D. J. Benos. 1988. Characteristics and regulatory mechanisms of the amiloride-blockade $\mathrm{Na}^{+}$channel. Physiol. Rev. 68:309-373.

37. Olver, R. E., C. A. Ramsden, L. B. Strang, and D. V. Walters. 1986. The role of amiloride-blockable sodium transport in adrenaline-induced lung liquid reabsorption in the fetal lamb. $J$. Physiol. (Lond.). 376:321-340.

38. Sano, K., G. R. Cott, D. R. Voelker, and R. J. Mason. 1988. The $\mathrm{Na}^{+} / \mathrm{H}^{+}$ antiporter in rat alveolar type II cells and its role in stimulated surfactant secretion. Biochem. Biophys. Acta. 939:449-458.

39. Shell, D. N., D. Durham, S. S. Murphree, K. H. Muntz, and P. W. Shaul. 1992. Ontogeny of $\beta$-adrenergic receptors in pulmonary arterial smooth muscle, bronchial smooth muscle and alveolar lining cells in the rat. Am. J. Respir. Cell. Mol. Biol. 7:317-324.

40. Carstairs, J. R., A. J. Nimmo, and P. Barnes. 1985. Autoradiographic visualization of $\beta$-adrenoreceptor subtypes in human lung. Am. Rev. Respir. Dis. 132:541-547.

41. Fasabiak, J. P., E. S. Vesell, and D. E. Rannels. 1987. Interactions of $\beta$ adrenergic antagonists with isolated rat type II pneumocytes. I. Analysis, characterization and regulation of specific $\beta$-adrenergic receptors. J. Pharmacol. Exp. Ther. 241:722-727.

42. Casale, T. B., D. Wood, S. Wascott, and M. Kaliner. 1987. Immunohistochemical identification of lung cells responsive to $\beta$-stimulation with a rise in cAMP. J. Appl. Physiol. 63:434-439.

43. Fitzgerald, J. D., J. L. Wale, and M. Austin. 1972. The hemodynamic effect of propranolol, dexpropranolol, oxprenolol, practolol, and sotalol in anesthetized dogs. Eur. J. Pharmacol. 17:123-131.

44. Ariens, E. J., and A. M. Simonis. 1983. Physiological and pharmacological aspects of adrenergic classification. Biochem. Pharmacol. 32:1539-1545.

45. Sibley, D. R., and R. J. Lefkowitz. 1985. Molecular mechanisms of receptor desensitization using the $\beta$-adrenergic receptor coupled to adenylate cyclase system as a model. Nature (Lond.). 317:124-129.

46. Liggett, S. B., J. C. Marker, S. D. Shah, C. L. Roper, and P. E. Cryer. 1988. Direct relationship between mononuclear leukocyte and lung $\beta$-adrenergic receptors and apparent reciprocal regulation of extravasal but not intravascular alpha- and $\beta$-adrenergic receptors by the sympathochromaffin system in humans. J. Clin. Invest. 82:48-56.

47. DeBlasi, A., A. S. Maisel, R. D. Feldman, M. G. Ziegler, M. Fratelli, M. Dilallo, D. A. Smith, C. C. Lai, and H. J. Motulsky. 1986. In vivo regulation of $\beta$-adrenergic receptors on human mononuclear leukocytes: assessment of receptor number, location and function after posture change, exercise and isoproterenol infusion. J. Clin. Endocrinol. \& Metab. 63:847-853.

48. Padbury, J. F., C. J. Hobel, R. W. Lam, and D. A. Fisher. 1981. Sex differences in lung and adrenal neurosympathetic development in rabbits. Am. J. Obstet. Gynecol. 141:199-204.

49. Ekelund, R. L., R. Burgoyne, and G. Enhorning. 1983. Pulmonary surfactant release in fetal rabbits: immediate and delayed response to terbutaline. Am. J. Obstet. Gynecol. 147:437-443.

50. McDonald, J. V., L. W. Gonzales, P. L. Ballard, J. Pitha, and J. M. Roberts. 1986. Lung $\beta$-adrenoreceptor blockade affects perinatal surfactant release but not lung water. J. Appl. Physiol. 60:1727-1733.

51. Rubin, D. B., J. P. Wiener-Kronish, J. F. Murray, D. R. Green, J. Turner, J. M. Luce, A. B. Montgomery, J. D. Marks, and M. A. Matthay. 1990. Elevated von Willebrand factor antigen is an early plasma predictor of acute lung injury in nonpulmonary sepsis syndrome. J. Clin. Invest. 86:474-480. 